\title{
In-vivo Therapeutic Efficacy Trial with Artemisinin Derivative, Buparvaquone and Imidocarb Dipropionate against Babesia equi Infection in Donkeys
}

\author{
Sanjay KUMAR ${ }^{1)^{*}}$, Ashok K. GUPTA ${ }^{1)}$, Yash PAL ${ }^{1)}$ and Shailendra K. DWIVEDI ${ }^{1)}$ \\ ${ }^{1)}$ National Research Centre on Equines, Sirsa Road, Hisar 125 001. Haryana. India
}

(Received 20 January 2003/Accepted 22 July 2003)

\begin{abstract}
The therapeutic efficacy of imidocarb, artesunate, arteether, buparvaquone and arteether+buparvaquone combination was evaluated against Babesia equi of Indian origin in splenectomised donkeys with experimentally induced acute infection. Efficacies of these drugs were tested by administering each drug or drug combination to groups of donkeys (having three donkeys each group). One gr oup of donkey was kept as untreated control for comparing the results. Parasitaemia, haematology (WBC, RBC, PCV, granulocytes and h aemoglobin), biochemical parameters (SAST, SALT, alkaline phosphatase, albumin/globulin ratio) were monitored at regular intervals. Individually, arteether and buparvaquone were found to have no parasite clearing efficacy and the treated animals died within 5-6 days after showing high parasitaemia and clinical symptoms of the disease. However, artesunate treated animals were able to restrict the parasite multiplication but only during the treatment period. Animals treated with imidocarb and arteether+buparvaquone combination were able to clear the parasite from the blood circulation after 2-5 days post-treatment (PT). After 55-58 days PT, recrudescence of B. equi parasite was observed in both these groups and a mean survival period of 66 days and 69 days, respectively, was recorded in these groups. Results of haemato-biochemical parameters had shown that imidocarb had deleterious effect on the liver function while on the other hand arteether+buparvaquone combination was found to be safe. This limited study indicates that arteether+buparvaquone combination c ould be a better choice than imidocarb for treating $B$. equi infection, but further trials are required in detail.

KEY WORDS: artemisinin derivative, Babesia equi, buparvaquone, imidocarb dipropionate, treatment.
\end{abstract}

J. Vet. Med. Sci. 65(11): 1171-1177, 2003

Equine babesiosis is caused by Babesia equi and Babesia caballi and both protozoa are transmitted by the same tickvector in an endemic area and hence are closely associated. B. equi is more widely distributed than B. caballi [19] and is generally more resistant to treatment than B. caballi. Efficacy of many babesicidal drugs against $B$. caballi is well documented as compared to $B$. equi infections $[17,18]$. So far none of the drug has been found to completely cure the animals from $B$. equi. For treatment of equines infected with $B$. equi, repeated doses of the drug are usually used and this approach controls clinical infection but will not clear the parasite completely from the body. Imidocarb, the only drug of first choice against $B$. equi infection, is also partially successful in eliminating $B$. equi from the infected horses $[10,18]$. This drug has also been observed to be harmful to horses [1] and recrudescence of parasitemia in treated animals is common. Parvaquone and buparvaquone, antitheilerial agents, have also been tried against acute $B$. equi infection but with limited efficacy $[18,31]$. Recently, artemisinin (qinghaosu) derivatives viz. artesunate, arteether, artemether have been found very effective in treatment of multiple drug resistant human cases of falciparum malaria [5, 25, 29] and Babesia in in-vitro culture system (22). The aim of the present study was to test these new drugs against acute $B$. equi infection, experimentally produced in donkeys, and to compare their efficacy against imidocarb treated donkeys.

\footnotetext{
* Correspondence to: Dr. Kumar, S., National Research Center for Protozoan Diseases Obihiro University of Agriculture and Veterinary Medicine Inada-cho, Obihiro 080-8555, Hokkaido, Japan.
}

\section{MATERIALS AND METHODS}

Animals: Eighteen indigenous non-descript, healthy and $B$. equi-free donkeys 1.0 to 2.5 years of age, were used in the present drug trail. The Babesia equi free status of these donkeys was ascertained by testing their serum for the absence of specific antibodies by conducting Dot-ELISA [15]. These donkeys were randomly divided into six groups of three donkeys per group. All the donkeys were splenectomised under general anaesthesia [7]. The objective of the splenectomy was to induce acute $B$. equi infection and to relinquish the parasite clearing efficacy of body immune system so that potency of the drug(s) under test can be accurately assessed. After a suitable duration (5-7 days after surgery) of post-operative care, these were infected with $B$. equi parasite (Indian strain) [12] by intravenous inoculation of about $50 \mathrm{ml}$ blood, collected in acid citrate dextrose (ACD) solution from a known B. equi carrier donkey maintained at National Research Centre on Equines, Hisar, India.

Experimental design: Drug treatments in different groups were initiated when parasitaemia was between 6.4-12.5\% (refer Table 1) (defined as day '0'). Donkeys in group I were treated by inoculating imidocarb dipropionate (Imizol $^{\circledR}, \mathrm{M} / \mathrm{s}$ Schering-Plough Animal Health Corporation, Germany) at the dose rate of $5 \mathrm{mg} / \mathrm{kg}$ body weight with 4 doses at $72 \mathrm{hr}$ intervals. Group II donkeys were treated with artesunate (Falcigo ${ }^{\circledR}, \mathrm{M} / \mathrm{s}$ Zydus Cadila Health Care Limited, India) at the level of $2.5 \mathrm{mg} / \mathrm{kg}$ body weight daily for 4 days. Group III donkeys were treated by injecting arteether (E-Mal ${ }^{\circledR}, \mathrm{M} / \mathrm{s}$ Themis Laboratories Limited, India) at a dose rate of $5 \mathrm{mg} / \mathrm{kg}$ body weight daily for 3 days. Group IV 
donkeys were treated with buparvaquone $\left(\right.$ Butale $^{\circledR}, \mathrm{M} / \mathrm{s}$ Zydus Aqrovet, India) at a dose rate of $5 \mathrm{mg} / \mathrm{kg}$ body weight daily for 4 days. Group V donkeys were treated with arteether and buparvaquone combination at a dose rate and duration as mentioned above. Imidocarb dipropionate, artesunate and arteether were administered by intramuscular route while buparvaquone was given intravenous route. Group VI donkeys were kept as untreated control. Drug efficacy was defined as the mean percent suppression of parasitaemia as compared with non-treated control donkeys group (VI). It is to certify that the experiment was conducted as per the guidelines set by the Committee for the Purpose of Control and Supervision of Experiments on Animals (CPCSEA), Animal Welfare Division, Government of India. During the experiment, animals were treated humanely as per the procedure approved by Institutional Animal Ethic Committee (IAEC).

Blood samples and clinical observations: Initially, blood and serum samples, both for haematology and biochemical analysis were collected respectively in heparinised vaccutainers (Vacuette ${ }^{\circledast}$ Greiner GmbH, Germany) and serum collection tubes from all the donkeys daily for a week, then twice a week up to 35 days post-treatment (PT). Parasitaemia in peripheral circulation was monitored throughout the observation period by making a thin blood smear from a drop of blood from the tip of ear and its percentage was determined by counting at least about 2000 erythrocytes per stained smear. After recrudescence of parasitaemia, samples were collected twice a week until recovery or death.

Haematological parameters: Haemoglobin $(\mathrm{Hb}, \mathrm{g} / \mathrm{d} l)$, packed cell volume (PCV, \%), red blood cell count (RBC, $10^{6} / \mathrm{cmm}$ ), white blood cell count (WBC, $10^{3} / \mathrm{cmm}$ ), granulocytes $(\%)$, lymphocytes $(\%)$, monocyte $(\%)$ were estimated in the blood of donkeys (Group I to VI) using MS 9VET Blood Cell Counter (M/s Melet Schloesting Laboratories, France).

Biochemical Parameters: Serum aspartate aminotransferase (SAST, IU/l), serum alanine aminotransferase (SALT, IU/l), serum alkaline phosphatase (SAP, IU/l), albu$\min (\mathrm{g} / \mathrm{d} l)$, total serum protein (TSP, $\mathrm{g} / \mathrm{d} l)$ were estimated using single step reagent kits (M/s Transasia Biomed Pvt Ltd, India) with the help of auto analyzer (M/s Biosystem BST-370, Germany). Globulin $($ TSP - albumin $=$ globulin $)$ and albumin/globulin $(\mathrm{A} / \mathrm{G})$ ratio was determined mathematically.

Statistical analysis: Data was subjected to statistical analysis by Student's $t$ test as described by Snedecor and Cochran [28].

\section{RESULTS}

Efficacy of different drugs with respect to clinical and haematological observations: Tables 1 and 2 present the information on drugs used and haematological observations. Imidocarb treated animals (group I) recovered from initial parasitaemia two days post-treatment (PT), but after 54 days of treatment recovery, recrudescence of parasitaemia was

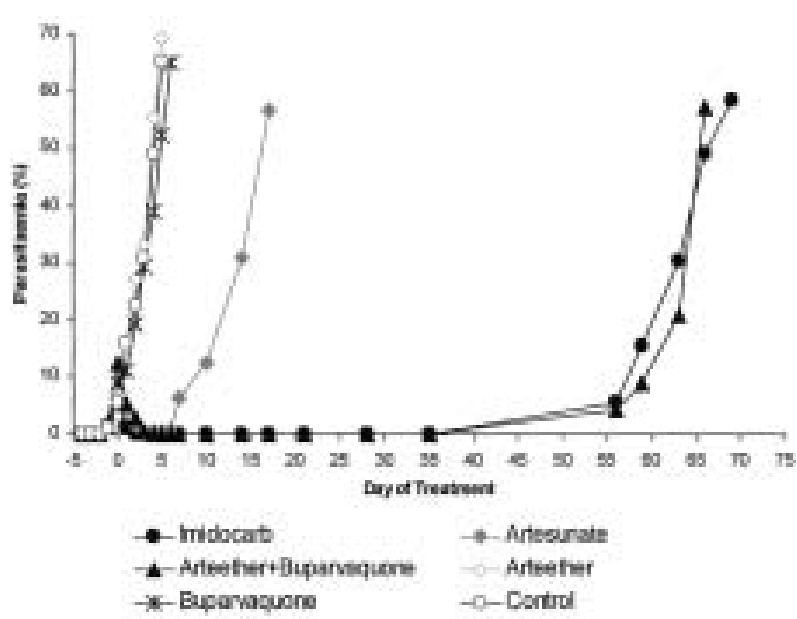

Fig.1. Per cent parasitaemia in the peripheral blood of Babesia equi infected groups during the treatment trial with various drugs.

observed. The mean PT survival period in this group was 69 days (ranged 66 to 71 days PT). In group II, artesunate was observed to restrict the multiplication of the parasite during the treatment regimen only, as initial parasitaemia decreased from $7.1 \%$ to $0.5 \%$ (Fig.1). But after completion of the regimen, the mean maximum parasitaemia increased to $56.7 \%$ between 16-19 days PT (mean 17 days PT) and subsequently all the treated donkeys died. In arteether only and buparvaquone only treated group (III and IV, respectively), no recovery was observed after treatment and they died after showing high parasitaemia as observed in control donkeys also (Table 1). In group V (arteether+buparvaquone combination) recovery after treatment was recorded as parasites were cleared after mean four days PT. However, recrudescence of parasitaemia was observed after mean 52 days PT (Table 1) and mean PT survival period was 66 days (ranged 64-68 days PT). All the donkeys in control group (group VI) died within 4 to 6 days of infection.

In group I donkeys, mean minimum haemoglobin value was $11.9 \mathrm{~g} / \mathrm{d} l$ after treatment which decreased to $11.2 \mathrm{~g} / \mathrm{d} l$ after treatment recovery period. Comparatively in group $\mathrm{V}$, a steep fall in haemoglobin mean values (from $11.8 \mathrm{~g} / \mathrm{d} l$ to $5.29 \mathrm{~g} / \mathrm{d} l$ on day $10 \mathrm{PT}$ ) was recorded, which was subsequently recovered to mean $10.2 \mathrm{~g} / \mathrm{d} l$ before recrudescence. After recrudescence haemoglobin level decreased drastically in both groups I and V (79.2\% and $65.6 \%$, respectively). In groups III and IV, acute fall in haemoglobin levels within 4 to 7 days after treatment was observed and mean haemoglobin concentrations before death were $2.5 \mathrm{~g} / \mathrm{d} l$ and $2.8 \mathrm{~g} / \mathrm{d} l$, respectively (Table 2 ). In group II, drop in haemoglobin was not severe during treatment regimen (from mean $14.7 \mathrm{~g} / \mathrm{d} l$ to $12.7 \mathrm{~g} / \mathrm{d} l$ on day $4 \mathrm{PT}$ ), but after treatment regimen a sharp fall was noticed.

Regarding packed cell volume (PCV), group V treated donkeys manifested a rapid fall after treatment and the mean minimum value on the tenth day PT was $16.0 \%$ as compared 
Table 1. Efficacy of different drugs against experimentally produced Babesia equi infection in splenectomised donkeys

\begin{tabular}{|c|c|c|c|c|c|c|c|c|}
\hline $\begin{array}{c}\text { Groups } \\
(\mathrm{n}=3)\end{array}$ & Drugs (trade name) & $\begin{array}{l}\text { Drug dosage } \\
\text { (mg/kg b.wt) \& } \\
\text { route }\end{array}$ & $\begin{array}{l}\text { No. of } \\
\text { injection }\end{array}$ & $\begin{array}{c}\% \\
\text { parasitaemia } \\
\text { on the day of } \\
\text { treatment }\end{array}$ & $\begin{array}{l}\text { Treatment } \\
\text { interval } \\
\text { (hr) }\end{array}$ & $\begin{array}{c}\text { Days } \mathrm{PT}^{\mathrm{a})} \\
\text { when animals } \\
\text { recovered*b) }\end{array}$ & $\begin{array}{r}\text { Mean } \\
\text { dura } \\
\text { tre }\end{array}$ & $\begin{array}{l}\text { duration after } \\
\text { treatment } \\
\text { (days) }\end{array}$ \\
\hline I & $\begin{array}{l}\text { Imidocarb } \\
\text { dipropionate } \\
\left(\text { Imizol }^{\circledR}\right)\end{array}$ & 7.0 (i.m.) & 4 & 6.4 & 72 & Yes (2 PT) & $\begin{array}{l}\text { Yes, } 52-56 \text { days after } \\
\text { treatment recovery }\end{array}$ & 69 \\
\hline II & $\begin{array}{l}\text { Artesunate, } \\
\text { artemisinin } \\
\text { derivative }\left(\text { Falcigo }^{\circledR}\right)\end{array}$ & 2.5 (i.m.) & 4 & 7.1 & 24 & No & $\begin{array}{l}\text { No, died between 16-19 } \\
\text { days PT }\end{array}$ & 17 \\
\hline III & $\begin{array}{l}\text { Arteether, } \\
\text { artemisinin synthetic } \\
\text { derivative } \\
\left(\mathrm{E} \mathrm{Mal}^{\circledR}\right)\end{array}$ & c 5.0 (i.m.) & 3 & 6.8 & 24 & No & $\begin{array}{l}\text { No, died between } 4-6 \\
\text { days PT }\end{array}$ & 5 \\
\hline IV & $\begin{array}{l}\text { Buparvaquone } \\
\left(\text { Butalex }^{\circledR}\right)\end{array}$ & 5.0 (i.v.) & 4 & 8.9 & 24 & No & $\begin{array}{l}\text { No, died between } 5-7 \\
\text { days PT }\end{array}$ & 6 \\
\hline V & $\begin{array}{l}\text { Arteether }+ \\
\text { Buparvaquone } \\
\left(\text { E Mal }^{\circledR}+\text { Butalex }^{\circledR},\right. \\
\text { as above) }\end{array}$ & $\begin{array}{l}5 \text { (i.m.) + } \\
5.0 \text { (i..v.) }\end{array}$ & $3+4$ & 12.5 & 24 (each) & Yes (4 PT) & $\begin{array}{l}\text { Yes, } 50-54 \text { days after } \\
\text { treatment recovery }\end{array}$ & 66 \\
\hline VI & Untreated Control & - & - & - & - & No & $\begin{array}{l}\text { No, died between } 4-6 \mathrm{da} \\
\text { of infection }\end{array}$ & 5 \\
\hline
\end{tabular}

a) PT: Post-treatment.

b) *: Recovery day was considered when no parasite could be observed in the blood smears after treatment.

Table 2. Clinical and haematological observations in different splenectomised Babesia equi infected donkeys group treated with various drugs

\begin{tabular}{|c|c|c|c|c|c|c|c|c|c|c|c|}
\hline \multirow{2}{*}{$\begin{array}{l}\text { Group } \\
\qquad(\mathrm{n}=3)\end{array}$} & \multicolumn{3}{|c|}{ Mean parasitaemia $(\%)$} & \multicolumn{4}{|c|}{ Mean haemoglobin $(\mathrm{g} / \mathrm{d} l)$} & \multicolumn{4}{|c|}{ Mean packed cell volume (\%) } \\
\hline & $\begin{array}{l}\text { On day } \\
\text { of } \\
\text { treatment }\end{array}$ & $\begin{array}{c}\text { Max. } \\
\text { after } \\
\text { treatment }\end{array}$ & $\begin{array}{l}\text { Max. } \\
\text { after } \\
\text { recrude- } \\
\text { scence }\end{array}$ & $\begin{array}{c}\text { On day } \\
\text { of } \\
\text { treatment }\end{array}$ & $\begin{array}{c}\text { Min. } \mathrm{Hb} \\
\text { during } \\
\mathrm{TR}^{\mathrm{a} / \mathrm{before}} \\
\text { death }\end{array}$ & $\begin{array}{l}\mathrm{Hb} \\
\text { before } \\
\text { recrude- } \\
\text { scence }\end{array}$ & $\begin{array}{l}\% \text { fall } \\
\text { after } \\
\text { recrude- } \\
\text { scence }\end{array}$ & $\begin{array}{l}\text { On day } \\
\text { of } \\
\text { treatment }\end{array}$ & $\begin{array}{c}\text { Min. PCV } \\
\text { during } \\
\mathrm{TR}^{\text {a) } / \text { before }} \\
\text { death }\end{array}$ & $\begin{array}{l}\mathrm{PCV} \\
\text { before } \\
\text { recrude- } \\
\text { scence }\end{array}$ & $\begin{array}{l}\% \text { fall } \\
\text { after } \\
\text { recrude- } \\
\text { scence }\end{array}$ \\
\hline I & 6.4 & $-{ }^{\text {b) }}(2)$ & $58.4(69)$ & 15.0 & $11.9(10)$ & 11.2 & 79.2 & 30.2 & $23.7(10)$ & 24.6 & 58.9 \\
\hline II & 7.1 & $56.7(17)$ & $\mathrm{NA}^{\mathrm{d})}$ & 14.7 & $3.1(17)$ & NA & NA & 40.9 & $10.7(17)$ & NA & NA \\
\hline III & 6.8 & $69.2(5)$ & NA & 9.0 & $2.5(5)$ & NA & NA & 24.8 & $6.9(5)$ & NA & NA \\
\hline IV & 8.9 & $64.9(6)$ & NA & 10.0 & $2.8(6)$ & NA & NA & 28.11 & $7.47(6)$ & NA & NA \\
\hline V & 12.5 & $-(4)$ & $57.2(66)$ & 11.8 & $5.2(10)$ & 10.2 & 65.6 & 40.2 & $16.0(10)$ & 36.0 & 72.9 \\
\hline VI & $\mathrm{NT}^{\mathrm{c})}$ & $65.2(5)$ & NA & 10.0 & $2.8(5)$ & NA & NA & 30.0 & $10.6(5)$ & NA & NA \\
\hline
\end{tabular}

a) TR: Treatment recovery.

b) '-' Indicates no parasite could be observed upon examining at least 20 field in stained blood smears under oil immersion.

c) NT: No treatment.

d) NA: Not applicable.

The values in parenthesis indicate the day of particular observation during post-treatment/post-infection.

to $23.7 \%$ in group I (Table 2). During the treatment recovery period, an improvement in PCV values (rose to $36.0 \%$ ) was observed in group $\mathrm{V}$ donkeys. After recrudescence PCV value decreased in both donkeys group I (from $24.6 \%$ to $10.1 \%)$ and $\mathrm{V}(36.0 \%$ to $9.75 \%)$ showing a per cent fall of $58.9 \%$ and $72.9 \%$, respectively.

An increase in mean white blood cell (WBC) count was observed in groups I and V donkeys after treatment, but the increase was more pronounced in group V (98\% increase PT) as compared to a $56.0 \%$ increase in group I donkeys (Fig. 2A). In group II donkeys, WBC decrease was noticed during the treatment schedule and thereafter a sharp increase was observed as in group III, IV and VI (Fig. 2A). Typically the lymphocyte count decreased in all treated groups after treatment (Fig. 2C). In group I and V, the per cent lymphocytes improved during the treatment recovery period but it 

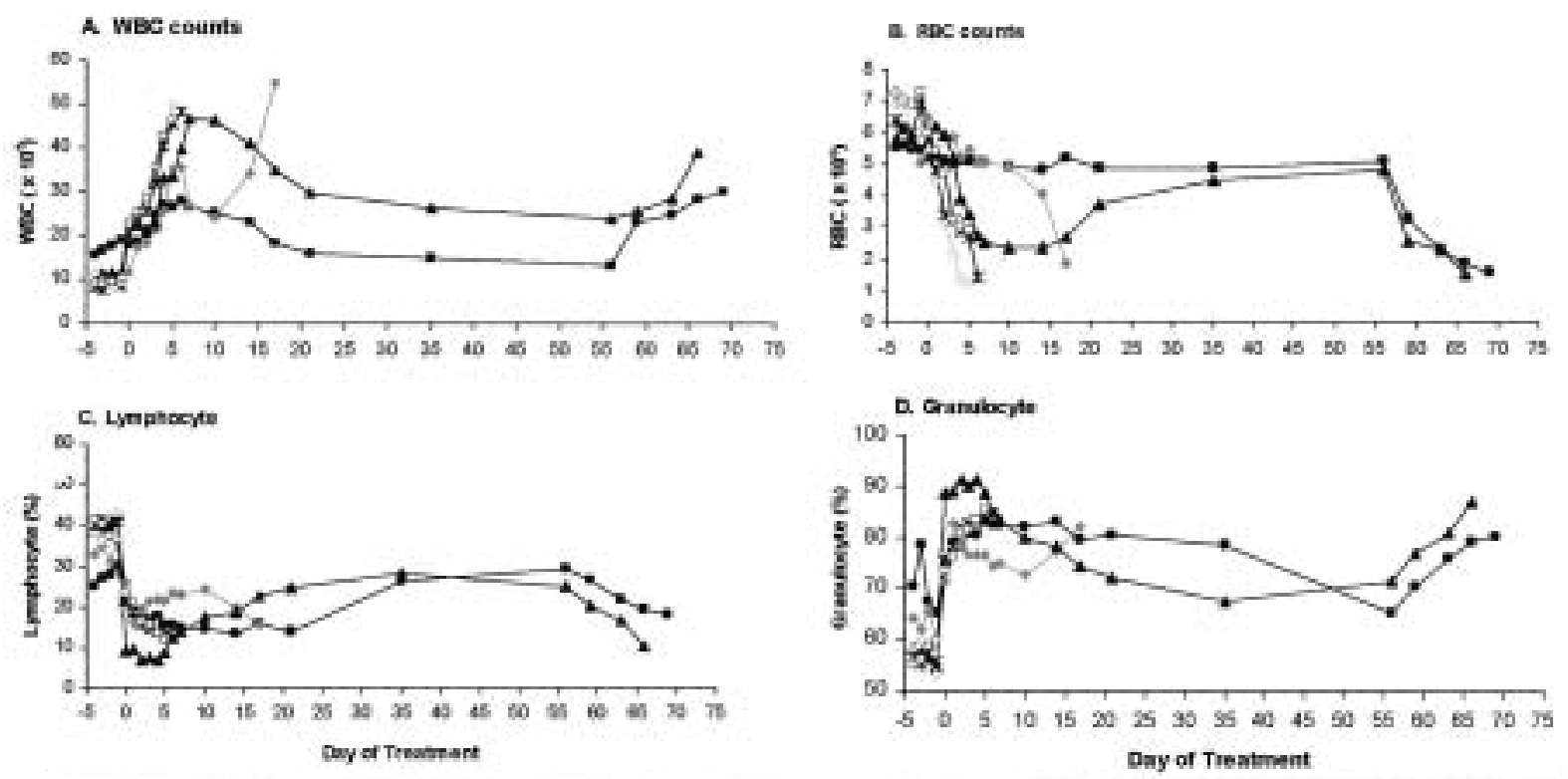

$\rightarrow$-Imidoearb $\rightarrow$ Artesunate $\rightarrow$ Artemisinin+Buparvaquone - Artemisinin $\rightarrow$-Buparvaquone $-O$-Control

Fig. 2. WBC counts (A), RBC counts (B), lymphocyte \% (C) and granulocyte \% (D) estimation in the blood of Babesia equi infected groups during the treatment trial with various drugs.

again declined after recrudescence. Increase in per cent granulocytes (Fig. 2D) occurred in all the treated donkeys groups. Granulocytes percentage was higher in group V (91.1\% on day 4PT) as compared to group I (83.0\% on day 14PT). Red blood cells (RBC) counts decreased almost in all the treated donkey's groups (Fig. 2B). In group V, it decreased to $3.7 \times 10^{6} / \mathrm{cmm}$ (on day 21PT) from the initial mean treatment value of $5.9 \times 10^{6} / \mathrm{cmm}$, while in group I, it decreased from initial mean value of $5.79 \times 10^{6} / \mathrm{cmm}$ to 4.82 $\times 10^{6} / \mathrm{cmm}$ (on day $\left.14 \mathrm{PT}\right)$.

Biochemical evaluations: In group I, after treatment a very sharp increase (about $86.7 \%$ ) in the activity of SAST was observed, as the level of enzyme increased from initial mean $481.0 \mathrm{IU} / l$ to mean $898.0 \mathrm{IU} / l$ on 14 th day PT IU/l (Fig 3A). In group $\mathrm{V}$, this increase was from mean 404.4 IU/l on ' 0 ' day to mean $474.6 \mathrm{IU} / l$ on day five PT while in artesunate treated donkeys, a minor decrease in SAST values i.e., from $500 \mathrm{IU} / l$ on day ' 0 ' to mean $464.6 \mathrm{IU} / l$ on third day PT was observed. In rest of the groups, after development of proliferative parasitaemia, a profound increase in SAST values was observed. After recrudescence in group I and V also, an increase in SAST values was observed. SALT values also increased in group I from mean 42.34 IU/ $l$ to mean $85.5 \mathrm{IU} / l$ on 14 day $\mathrm{PT}$, while in group $\mathrm{V}$, this increase was from mean $33.2 \mathrm{IU} / l$ to $70.8 \mathrm{IU} / l$ on day 4 th PT as compared to '0' day value. Increase in SAP activity was also observed during post treatment period. SAP values increased to $33.7 \%$ (mean value $191.7 \mathrm{IU} / l$ on 14 days PT) from the basal ' 0 ' day (mean $143.4 \mathrm{IU} / l$ ) values in group I as compare to $13.8 \%$ (mean $177.5 \mathrm{IU} / \mathrm{l}$ on 4 days PT) in group
$\mathrm{V}$ (on day ' 0 ' mean values were $155.9 \mathrm{IU} / \mathrm{l}$ ). Albumin/globulin $(\mathrm{A} / \mathrm{G})$ ratio decreased in all the donkeys groups (I to VI) indicating increase in globulin fraction in the serum (Fig. 3D). In group I, it decreased from initial mean value of 0.64 to 0.24 on day $69 \mathrm{PT}$, while in group $\mathrm{V}$ this decreased was from 0.48 to 0.34 ( 66 day PT).

\section{DISCUSSION}

Babesia equi is a known parasitic problem of equines and infection is worldwide. The importance lies in the fact that infected animals become carriers for life and potential intrauterine infection can occur throughout the breeding life of the mare. A high seroprevalence of $B$. equi antibodies have been reported in equids from many tropical countries specially India [15, 16], African continent and Madagaskar [8] and clinical cases are very often. Losses due to intrauterine infection leading to abortion and strong regulation on export of B. equi carrier equine species are relatively common. None of the drugs tested so far have been observed to be effective in clearing the parasite. In this paper, an attempt was made to study the efficacy of new anti-theilerial and anti-malarial drugs against experimental $B$. equi infection either individually or in combinations.

No literature is available regarding the in-vivo therapeutic efficacy of new anti-malarial artemisinin derivatives (artesunate and arteether) against any intraerythrocytic haemoprotozoan of horse or cattle. Although growth inhibition efficacy of artesunate against equine's Babesia in in-vitro culture has been demonstrated by Nagai et al., 2003 [22]. 

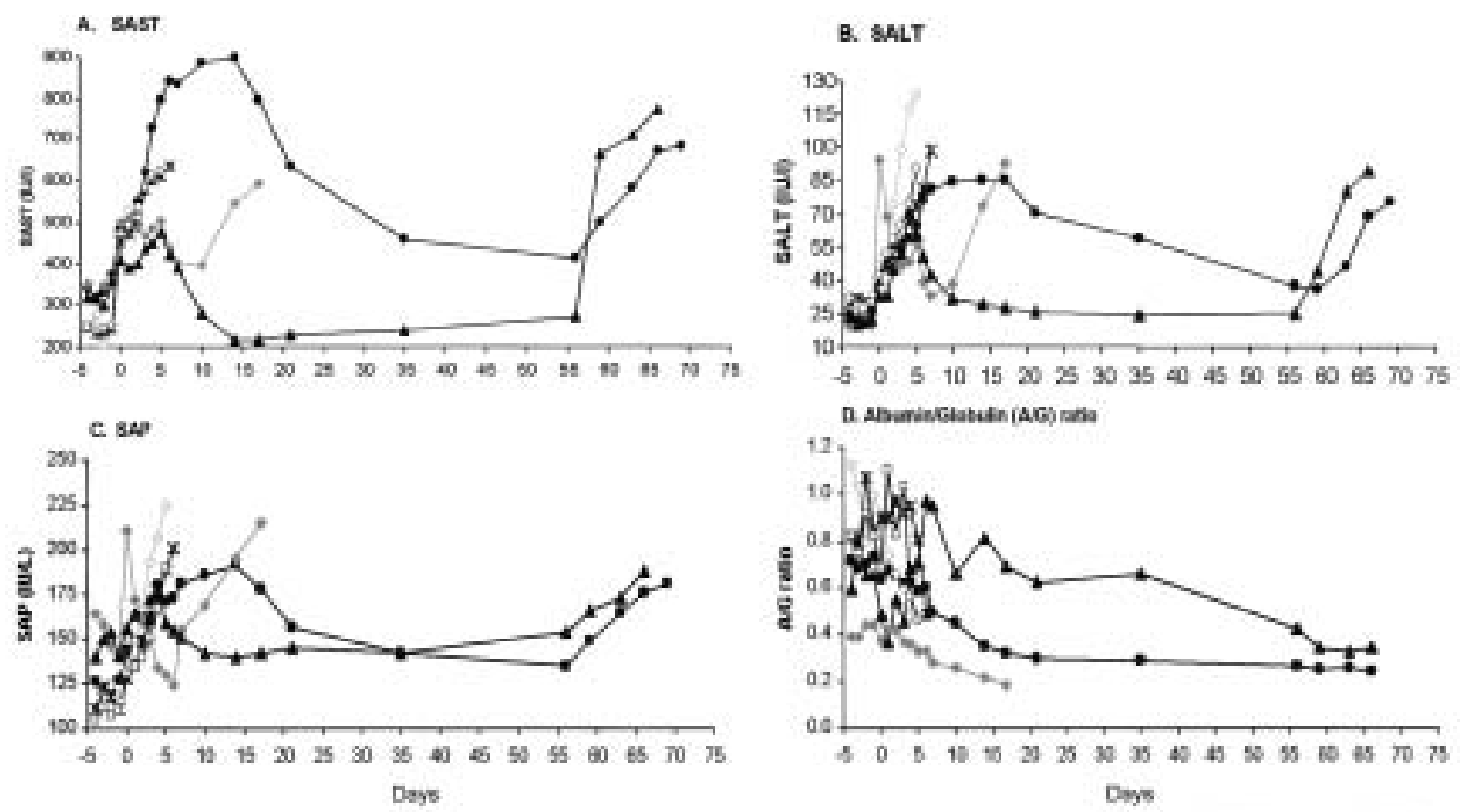

- Imidocarb - - Artesunate - Artemisinin+Buparvaquone - Artemisinin $-\alpha$-Buparvaquone $-C$-Control

Fig. 3. Activities of SAST (A), SALT (B), SAP (C) and A/G ratio (D) in the serum of Babesia equi infected groups during the treatment trial with various drugs.

We used $2.5 \mathrm{mg} / \mathrm{kg} \mathrm{b}$. wt and $5 \mathrm{mg} / \mathrm{kg} \mathrm{b}$. wt dose rate for artesunate and arteether, respectively. It was selected by doubling the effective therapeutic dosage as used in human beings $[2,27,32]$. Imidocarb dosage was based on the previous studies in horses and donkeys [10, 24, 26]. Buparvaquone was used at previously suggested dosage in splenectomised B. equi infected horses [31]. A slight swelling at injection site and restlessness were noticed after intramuscular imidocarb inoculation while no such reaction could be appreciated after inoculation of artesunate or arteether or bupavaquone or arteether + buparvaquone, in the present study.

Individually arteether and buparvaquone were found ineffective in suppressing the fulminating parasitaemia. However, a synergistic effect was recorded in terms of parasite clearing efficacy when combination of arteether and buparvaquone were used at the same individual dose rate. It is difficult to explain the mechanism of this synergism (arteether and buparvaquone) in the present study. Buparvaquone acts selectively against the parasite's electron transport system at ubiquinone-cytochrome c reductase of the respiratory chain $[14,11]$ while artemisinin-type compounds are found to block heme polymerization, causing a buildup of monomeric free heme toxic to the parasite [23]. Hence the combination might have worked well to suppress the increasing parasitaemia. Nagai et al. [22] reported complete growth inhibition of $B$. equi in in-vitro culture system at $12.44 \mu \mathrm{g} / \mathrm{m} l$ of artesunate concentration, while in the present study a transient in-vivo growth inhibition effect of artesunate was observed. Similar transient in-vivo efficacy of the artesunate against Babesia microti in the hamster model has been observed by Marley et al. [21].

Simultaneously fall in haematocrit and haemoglobin in donkeys treated with arteether+buparvaquone combination was appreciably more than imidocarb treated donkeys. Recent studies suggested that artemisinin induces a decrease in parasitized erythrocytes deformability, hence more likely to be disrupted during their blood capillary passage or can be selectively destroyed by the immune system [6]. A transient decrease in haematocrit values in arteether+buparvaquone combination group may be due to this phenomenon, enabling clearance of parasitized erythrocytes, but body recoup the RBC counts to pre-treatment levels within few days after withdrawal of treatment regimen (Fig. 2). Further, per cent granulocyte (Fig. 2) and Babesia equi specific IgG levels (detected by performing Dot-ELISA, data not shown) during the first seven days after treatment in arteether+buparvaquone treated donkeys (Dot-ELISA titre ranged from $1: 3,200$ to $1: 12,800$ ) was more pronounced as compared to the imidocarb treated group (Dot-ELISA titre ranged from 1:3,200 to $1: 6,400)$.

Elevation of SAST, SALT and SAP levels in imidocarb treated group indicates hepatocellular damage beside damage to skeletal/cardiac muscles, osteoblast and intestine membranes [3, 4]. Frerich et al. [10] reported that liver of imidocarb treated horses has highest drug concentration up 
to 6 days after first injection. Adams [1] also observed elevated SAST, SALT and SDH levels in horses treated with imidocarb. He reported that imidocarb toxicity mortality is attributed to acute renal cortical tubular necrosis and acute periportal hepatic necrosis. The dose rate selected for arteether and artesunate was lower than the previous reported neurotoxic, anorectic toxic dosage (> $25 \mathrm{mg} / \mathrm{kg} /$ day multiple doses of arteether) in rats [20]. Buparvaquone has been reported to be safe when tried in Bo-RBC-SCID mouse model against Theileria sergenti [13] and in horses and ponies [31].

Decrease in A/G ratio indicates hyperglobinemia. A decrease in albumin level and increase in globulin fraction in the serum was observed in all the donkeys groups. De Waal et al. [9] and Yeruham et al. [30] also recorded similar observations during B. equi and Babesia ovis infection in horses and sheep, respectively.

In conclusions, we demonstrated that giving repeated doses of imidocarb or combination of arteether and buparvaquone at appropriate time interval and dose rate could control the B. equi (Indian origin) parasitemia in infected donkeys. However, arteether and buparvaquone combination was observed to be safer than imidocarb alone. Further more in-vivo trial would be required in splenectomised and non-splenectomised animal species to examine various dosages of arteether+buparvaquone and their side effects before this drug combination can be applied on infected animals in field.

ACKNOWLEDGEMENTS. Authors are thankful to the Director, NRCE, Hisar for providing all the necessary facilities for conducting this experiment. Thanks are also due to Sh. Sanjeev Chhabra and Sh. Ajmer Singh for technical assistance provided during the experiment.

\section{REFERENCES}

1. Adams. 1981. Clinicopathological aspects of imidocarb dipropionate toxicity in horses. Res. Vet. Sc. 31: 54-61.

2. Asthana, O. P., Srivasatava, J. S., Pandey, T. K., Viswanathan, K.A., Dev, V., Mahapatra, K. M., Nayak, N. C., Balsara, A. B., Mandal, O. P., Gupta, N., Mishra, S. K., Mohanty, S., Sathpathy, S., Das, B. S., Patnaik, J. K., Satpathy, S. K. and Dash, B. 2001. Multicentric clinical trials for safety and efficacy evaluation of alpha; beta arteether in complicated P. falciparum malaria. J. Assoc. Phy. India 49: 1155-1160.

3. Baeur, J. E. 1984. Clinical chemistry reference of foals during the first year of life. Equine Vet. J. 16: 361-362.

4. Blackmore, D. J. and Brobst, D. 1981. A booklet on biochemical values in equine medicine. The Animal Health Trust, U.K.

5. Bunnag, D., Karbwang, J. and Harinasuta, T. 1992. Artemether in the treatment of multiple drug resistant falciparum malaria. Southeast. Asian. J. Trop. Med. Public Health 23: 762-767.

6. Chotivanich, K., Udomsangpetch, R., Dondorp, A., Williams, T., Angus, B., Simpson, J.A., Pukrittayakamee, S., Looareesuwan, S., Newbold, C.I. and White, N.J. 2000. The mechanisms of parasite clearance after antimalarial treatment of Plasmodium falciparum malaria. J. Infect. Dis. 182: 629-633.

7. Dennig, H. K. and Brocklesby, D. W. 1965. Splenectomy of horses and donkeys. Vet. Rec. 77: 4045.

8. De Waal, D. T. and van Heerden, J. 1994. Equine babesiosis. In: Infectious diseases of livestock with special reference to Southern Africa (Coetzer, J.A.; Thomson, G. R. and Tustin, R. C. eds.), Oxford University Press.

9. De Waal, D. T., van Heerden, J. and Potgieter, F. T. 1987. An investigation into the clinical pathological changes and serological response in horses experimentally infected with Babesia equi and Babesia caballi. Onderstepoort J. Vet. Res. 54: 561-568.

10. Frerichs, W. M., Allen, P. C. and Holbrook, A. A. 1973. Equine piroplasmosis (Babesia equi) : Therapeutic trials of imidocarb dihydrochloride in horses and donkeys. Vet. Rec. 93: 73-75.

11. Fry, M. and Williams, R.B. 1984. Effects of decoquinate and clopidol on electron transport in mitochondria of Eimeria tenella (Apicomplexa: Coccidia). Biochem. Pharmacol. 33: 229-240.

12. Gautam, O. P, and Dwivedi, S. K. 1976. Equine babesiosis : A severe out-break in a stud farm at Hissar. Indian Vet. J. 53: $546-551$.

13. Hagiwara, K., Tsuji, M., Ishihara, C., Tajima, M., Kurosawa, T., Iwai, H. and Takahashi, K. 1993. The Bo-RBC-SCID mouse model for evaluating the efficacy of anti-theilerial drugs. Int. J. Parasitol. 23: 13-16.

14. Hudson, A. T., Randall, A. W., Fry, M., Ginger, C. D., Hill, B., Latter, V. S., McHardy, N. and Williams, R. B. 1985. Novel anti-malarial hydroxynpahthoquinones with potent broad spectrum anti-protozoal activity. Parasitology 90: 45-55.

15. Kumar, S., Malhotra, D. V. and Dhar, S. 1997. Serodiagnosis of Babesia equi infection-a comparison of Dot-ELISA, complement fixation test and capillary tube agglutination test. Vet. Parasitol. 69: 171-176.

16. Kumar, S., Kumar, Y., Malhotra, D. V., Dhar, S. and Nichani, A. K. 2003. Standardisation and comparison of serial dilution and single dilution enzyme linked immunosorbent assay (ELISA) using different antigenic preparations of Babesia (Theileria) equi parasite. Vet. Res. 34: 71-83.

17. Kuttler, K. L. 1981. Chemotherapy in babesiosis: A Review. pp. 65-85. In: (Ristic, M. and Kreir, J. P. eds.), Babesiosis. New York: Academic Press Inc.

18. Kuttler, K. L., Zaugg, J. L. and Gipson, C. A. 1987. Imidocarb and parvaquone in the treatment of piroplasmosis (Babesia equi) in equids. Am. J. Vet. Res. 48: 1613-1616.

19. Levine, N. D. 1985. Veterinary Protozoology. Ames, Iowa, Iowa State University Press.

20. Li, Q.G., Brueckner, R.P., Peggins, J.O., Trotman, K.M. and Brewer, T.G. 1999. Arteether toxicokinetics and pharmacokinetics in rats after $25 \mathrm{mg} / \mathrm{kg} /$ day single and multiple doses. Eur J. Drug. Metab. Pharmacokinet. 24: 213-223.

21. Marley, S. E., Eberhard, M. L., Steurer, F. J., Ellis, W.L., McGreevy, P. B. and Ruebush, T. K. II. 1997. Evaluation of selected antiprotozoal drugs in the Babesia microti-hamster model. Antimicrob. Agents. Chemother. 41: 91-94.

22. Nagai, A., Yokoyama, N., Matsuo, T., Bork, S., Hirata, H., Xuan, X., Zhu, Y., Claveria, F.G., Fujisaki, K. and Igarashi I. 2003. Growth-inhibitory effects of artesunate, pyrimethamine, and pamaquine against Babesia equi and Babesia caballi in in vitro cultures. Antimicrob. Agents. Chemother. 47: 800-803.

23. Olliaro, P. L., Haynes, R. K., Meunier, B. and Yuthavong, Y. 2001. Possible modes of action of the artemisinin-type compounds. Trends. Parasitol. 17: 122-126.

24. Petrovskii, V. V. 1975. Dynamics of complement-fixing anti- 
bodies in horses with Nuttallia (Babesia) equi infection and ways of curing the infection. Veterinariya 9: 68-70.

25. Pittler, M.H. and Ernst, E. 1999. Artemether for severe malaria: a meta-analysis of randomized clinical trials. Clin. Infect. Dis. 28: 597-601.

26. Singh, B., Banerjee, D. P. and Gautam, O. P. 1980. Comparative efficacy of diminazene diaceturate and imidocarb dipropionate against Babesia equi infection in donkeys. Vet. Parasitol. 7: 173-179.

27. Singh, N., Shukla, M. M., Asthana, O. P. and Sharma, V. P. 1998. Effectiveness of alpha-beta arteether in clearing Plasmodium falciparum parasitemia in central India (Madhya Pradesh). Southeast Asian. J. Trop. Med. Public Health 29: 225-227.

28. Snedecor, G. W. and Cochran W. G. 1989. Statistical methods.
Affiliated East-West Press Pvt. Ltd., New Delhi.

29. Taylor, T. E., Wills, B. A., Courval, J. M. and Molyneux, M. E. 1997. Intramuscular artemether vs intravenous quinine: an open, randomized trial in Malawian children with cerebral malaria. Trop. Med. Int. Health 3: 3-8.

30. Yeruham, I., Hadani, A., Galker, F., Avidar, Y. and Bogin, E. 1998. Clinical, clinico-pathological and serological studies of Babesia ovis in experimentally infected sheep. Zentralbl. Veterinarmed. 45: 385-394.

31. Zaugg, J. L. and Lane, V. M. 1992. Efficacy of buparvaquone as a therapeutic clearing agent of Babesia equi of European origin in horses. Am. J. Vet. Res. 53: 1396-1399.

32. Zhao, Y. 1985. Studies on systemic pharmacological effects of artesunate. J. Trop. Med. Hyg. 88: 391-396. 